\title{
O princípio da não discriminação e a inclusão socioecônomia da pessoa transexual no mercado formal de trabalho
}

\author{
Carla Vieira de Souza ${ }^{1}$ \\ Rodrigo Goldschmidt ${ }^{2}$
}

\begin{abstract}
Resumo: O presente artigo objetiva discorrer sobre o princípio da não discriminação, mais especificamente a igualdade de tratamento das pessoas transexuais. Ainda, aborda-se sobre a conceituação da transexual, sua identidade de gênero e as discriminações que sofrem. $\mathrm{O}$ artigo pontua, no último item, o trabalho formal como um meio de inclusão socioeconômica para as transexuais, abordando institutos do âmbito nacional e internacional. O problema de pesquisa baseia-se se a discriminação é um fator inerente para o difícil acesso das pessoas transexuais ao mercado de trabalho formal. Para tanto, o trabalho adota o método dedutivo e a pesquisa realizada é bibliográfica e documental.

Palavras-chave: Identidade de gênero. Inclusão Socioecônomica. Mercado formal de Trabalho. Transexual. Princípio da não discriminação.
\end{abstract}

The principle of non-discrimination and the socioeconomic inclusion of the transsexual person in the formal job market

\begin{abstract}
This article aims to discuss about the principle of non-discrimination, more specifically the equality of treatment of transsexual people. Also, it is about the conceptualization of the transsexual, it's gender identity and the discriminations that they suffer. Finally, the article points out the formal job as the means of socioeconomic inclusion for transsexuals, addressing institutes of national and international levels. The problem of research is based on the hypothesis of the discrimination to be a factor inherent for the difficult access of transsexual people to the formal job market. For this, the work adopts the deductive method and the research made is bibliographical and documental.

Keywords: Gender identity. Socioeconomic Inclusion. Formal Job Market. Transsexual. Principle of non-discrimination.

El principio de la no discriminación y la inclusión socieconómica de la persona transexual en el mercado formal de trabajo
\end{abstract}

Resumen: El presente artículo tiene por objeto discurrir sobre el principio de no discriminación, más específicamente la igualdad de trato de las personas transexuales. Se aborda sobre la conceptualización de transexual, su identidad de género y las discriminaciones que sufren las personas transexuales. El artículo puntualiza, en el último ítem, el trabajo formal como un medio de inclusión socioeconómica para las transexuales, abordando institutos del ámbito nacional e internacional. El problema de la investigación se basa si la discriminación es un factor inherente al difícil acceso de las personas transexuales al mercado de trabajo formal. Para ello, el trabajo adopta el método deductivo y la investigación realizada es bibliográfica y documental.

Palabras clave: Identidad de género. Inclusión Socioeconómica. Mercado formal de trabajo. Transexual. Principio de no discriminación.

\footnotetext{
${ }^{1}$ Advogada, Pós-Graduada em Direito e Processo do Trabalho pela Faculdade Damásio de Jesus e Mestranda em Direiro na UNESC.

${ }^{2}$ Pós-Doutor em Direito pela PUC/RS. Doutor em Direito pela UFSC. Professor e Pesquisador do PPGD/UNESC. Juiz do Trabalho Titular do TRT12.
} 


\section{Introdução}

Discriminar, de forma ilícita, denegrindo e prejudicando o outro por diferenças a partir de um julgamento moral negativo é um ato ilegal, sendo vedado pelo Direito, devendo ser combatido pelo Estado e pela sociedade.

A Constituição brasileira prevê diversos direitos, sendo que todas as pessoas merecem igualdade de tratamento, independente da cor de pele, idade, sexo, condição social, etc. Assim, há o chamado princípio da não discriminação, que visa concretizar e ressaltar o direito de não ser discriminado.

Ocorre que quando se refere às pessoas transexuais esse direito não é observado, pois elas sofrem discriminações em várias esferas da sociedade, seja na família, na escola, nas redes de atendimento a saúde, no trabalho e em outros círculos de relacionamento.

As transexuais ultrapassam a imposição binária de gênero (divisão do gênero humano em apenas homem ou mulher). Essa divisão é uma construção social que visa impor a heterossexualidade como incontestável, não havendo espaço e aceitação cultural para outras espécies de autodeterminação de gênero.

Assim, o presente trabalho objetiva discorrer sobre o princípio da não discriminação e sua aplicação para as pessoas transexuais. Visa ainda demonstrar a conceituação de transexual, sua identidade de gênero pautada na teoria queer e as discriminações existentes, bem como abordar o trabalho formal como um meio de inclusão socioeconômica.

Registre-se, ainda, que o trabalho adota o método dedutivo e a pesquisa realizada é bibliográfica e documental.

\section{Referencial Teórico}

\subsection{Do princípio da não discriminação}

Todas as pessoas possuem direitos de forma igualitária, assim previstos no plano do direito formal, conforme preconiza o artigo $3^{\circ}$, inciso IV da Constituição Federal brasileira ${ }^{3}$, não podendo haver discriminação por preconceito de sexo, raça, cor, entre outros. Ainda no

\footnotetext{
${ }^{3}$ Art. $3^{\circ}$ Constituem objetivos fundamentais da República Federativa do Brasil: IV - promover o bem de todos, sem preconceitos de origem, raça, sexo, cor, idade e quaisquer outras formas de discriminação.
} 
texto constitucional, o artigo $5^{0^{4}}$ salienta que deve haver igualdade de tratamento de todos, sem distinção de qualquer natureza.

$\mathrm{O}$ artigo $7^{05}$ da Carta Magna, em seus incisos, prevê a proteção ao trabalho da mulher, a proibição de diferenças de salários, de exercício de funções e critérios de admissões por motivo de sexo, idade, cor ou estado civil, proibição de discriminação do trabalhador deficiente, proibição de distinção entre trabalho manual, técnico ou intelectual e proteção do trabalho da criança e adolescente.

A Declaração Universal dos Direitos Humanos também estipula em seu artigo $23^{\circ}$ que: "1.Toda a pessoa tem direito ao trabalho, à livre escolha do trabalho, a condições equitativas e satisfatórias de trabalho e à proteção contra o desemprego. 2.Todos têm direito, sem discriminação alguma, a salário igual por trabalho igual" (UNITED NATIONS, 1948).

Para se compreender o Direito da Antidiscriminação é necessário entender o que seria discriminação, especificamente discriminação do mercado de trabalho, noções essas, basilares para esta pesquisa. Com esse propósito, o artigo $1^{\circ}$ da Convenção $\mathrm{n}^{\mathrm{o}} 111$ da Organização Internacional do Trabalho (OIT), promulgada pelo Brasil no ano de 1968, estabelece que a discriminação é: “Toda distinção, exclusão ou preferência fundada na raça, cor, sexo, religião, opinião política, ascendência nacional ou origem social, que tenha por efeito destruir ou alterar a igualdade de oportunidades ou de tratamento em matéria de emprego ou profissão" (BRASIL, 1968).

Em linhas gerais, extraindo-se do dispositivo supramencionado, discriminação seria toda atitude de excluir ou dar preferência à determinada pessoa, pautada na cor da pele, sexo, credo, opinião política, condição social, entre outros, a fim de boicotar a igualdade de tratamento entre os seres humanos.

\footnotetext{
${ }^{4}$ Art. $5^{\circ}$ Todos são iguais perante a lei, sem distinção de qualquer natureza, garantindo-se aos brasileiros e aos estrangeiros residentes no País a inviolabilidade do direito à vida, à liberdade, à igualdade, à segurança e à propriedade, nos termos seguintes.

${ }^{5}$ Art. $7^{\circ}$ São direitos dos trabalhadores urbanos e rurais, além de outros que visem à melhoria de sua condição social: XX - proteção do mercado de trabalho da mulher, mediante incentivos específicos, nos termos da lei; XXX - proibição de diferença de salários, de exercício de funções e de critério de admissão por motivo de sexo, idade, cor ou estado civil; XXXI - proibição de qualquer discriminação no tocante a salário e critérios de admissão do trabalhador portador de deficiência; XXXII: proibição de distinção entre trabalho manual, técnico ou intelectual ou entre os profissionais respectivos; XXXIII - proibição de trabalho noturno, perigoso ou insalubre a menores de dezoito e de qualquer trabalho a menores de dezesseis anos, salvo na condição de aprendiz, a partir de quatorze anos;
} 
De outra sorte, preconceito é um conceito geral que se refere à concepção mental negativa que se atribuem a determinadas pessoas ou grupos socialmente inferiorizados. A discriminação, por seu turno, é algo mais palpável, é a efetivação material do preconceito, através de atitudes arbitrárias, sejam de ação ou omissão, que violam os direitos dos grupos ou indivíduos (RIOS, 2008).

Considerando-se os ditames do direito norte-americano, a discriminação pode ser subdivida em duas espécies, denominadas de direta e indireta. A primeira se refere às práticas intencionais e conscientes dos agentes, e a segunda se dá por uma realidade histórica que se reproduz no tempo e continua permeando atitudes aparentemente neutras, mas que possuem cunho eminentemente discriminatório (RIOS, 2008).

Há ainda a discriminação negativa que atinge diretamente o princípio de igualdade de tratamento, calcada em uma motivação ilegítima, para manter determinadas pessoas ou grupos sociais subordinados. Já a discriminação positiva é um ato legítimo, posto que cria uma vantagem temporária ou permanente a determinados grupos sociais que estão em situação de vulnerabilidade e necessitam da atuação estatal para adquirirem a igualdade material (MOREIRA, 2017).

De acordo com Moreira (2017, p. 27) a discriminação: “indica que uma pessoa impõe a outra um tratamento desvantajoso a partir de um julgamento moral negativo". Ainda, o ato de discriminar está relacionado, muitas vezes, com a preservação de certos grupos sociais para manterem seus privilégios e os demais em uma situação de subordinação.

Fazendo-se um recorte específico para o presente artigo, as transexuais sofrem discriminação negativa direta e indiretamente por sua identidade de gênero. Para Moreira (2017, p. 33), o sexismo não é apenas uma prática discriminatória, "são verdadeiros sistemas de dominação social porque influenciam diferentes aspectos da vida dos indivíduos”.

Assim, cria-se uma desigualdade de status cultural e desigualdade de status material, ambas construídas por grupos sociais, culturalmente intencionados para praticarem a discriminação. A discriminação também opera para impedir a realização de igualdade de tratamento para as pessoas discriminadas, objetivando não permitir acesso às mesmas oportunidades (MOREIRA, 2017).

Os discriminados pela orientação sexual, por exemplo, são historicamente e propositalmente tratados desigualmente por parte da maioria, são estigmatizados, objetos de preconceito e hostilidade, recebem estereótipos que denigrem sua imagem atribuindo falta de capacidade, participação política mínima, possuem características de identidade próprias que 
não pretendem alterar e, por fim, a causa da discriminação é devida, haja visto que a participação do referido grupo não é algo positivo para a sociedade (RIOS, 2008).

$\mathrm{O}$ direito da antidiscriminação é respeitar igualmente todas as pessoas, oferecendo oportunidades e acesso a todos. Assim, “[...] apesar das desigualdades, das diferenças, da diversidade de cada realidade, todas as pessoas devem ter as mesmas oportunidades, para que possam alcançar uma vida condizente com a igual dignidade que todas possuem" (GOLDSCHMIDT; RENCK, 2016, p. 17).

Com isso, ser respeitado é um direito, pois todos os seres humanos merecem igualdade de tratamento e oportunidades, a fim de verem sua dignidade respeitada frente ao direito da antidiscriminação.

Colocadas essas considerações, no tópico seguinte tratar-se-á sobre quem são as transexuais, como se identificam como sujeitos e qual sua identidade de gênero, para melhor compreender a inclusão socioeconômica desse grupo.

\subsection{Das pessoas transexuais}

Para se compreender o conceito de transexual é necessário adentrar sobre identidade de gênero pautada na teoria queer, a fim de entender com profundidade esse grupo de pessoas.

Segundo Butler (2016), gênero é uma construção social e não se trata de resultado casual do sexo, tampouco pode ser considerado como binário, sendo designado como feminino ou masculino. Assim, nem sempre corpos masculinos são "homens" e corpos femininos são "mulheres".

Para Butler: "Quando o status construído do gênero é teorizado como radicalmente independente do sexo, o próprio gênero se torna um artifício flutuante, com a consequência de que homem e masculino podem, com igual facilidade, significar tanto um corpo feminino como um masculino, e mulher e feminino, tanto um corpo masculino como um feminino" (2016, p. 26).

Esta construção social do sujeito em gênero já inicia desde quando o ser humano é uma criança, competindo aos pais a responsabilidade de orientar seus filhos, pautados na anatomia de seu corpo, em se tornarem do gênero masculino ou feminino (BADINTER, 1993).

A cultura predominante aduz que é incompreensível haver pessoas que identificam seu gênero ao oposto do decorrente do sexo. Para tanto, essas identidades de gênero, 
culturalmente impostas, são problemas de desenvolvimento ou impossibilidades lógicas, pois são inteligíveis culturalmente na sociedade (BUTLER, 2016).

Neste sentido, a célebre frase de Simone de Beauvoir: "ninguém nasce mulher, tornase mulher" (2016, p. 11) corrobora com a identidade de gênero para explicar as pessoas transexuais. Para Beauvoir (2016), o gênero é sempre adquirido através de uma cultura variante, sendo que o sexo é imutável, mas o gênero não, rompendo também com a imposição binária.

Esta divisão em gênero e sexo masculino e feminino é algo imposto para declarar e afirmar a naturalidade da heterossexualidade, negando as demais afirmações de gêneros existentes. A lésbica se opõe a esta dualidade e não se declara como homem ou mulher, ela não tem sexo, está além destas categorias. Assim, ela pode tornar-se feminina, ser homem ou mulher, devido à constituição cultural do gênero (WITTIG, 2006).

Para Butler (2016), existe um terceiro gênero, como as lésbicas, gays, travestis, além também da performance de gênero, que se trata da imitação do gênero, como a $\operatorname{drag}^{6}$. A heterossexualidade não deve ser fixa e imutável, as configurações de gênero e sexo podem se proliferar para tentar combater o chamado "inatural” do gênero não binário.

De acordo com Bento:

Esses processos corporais podem ser pensados como metáfora para a construção de identidade. Ser um homem/uma mulher implica um trabalho permanente, uma vez que não existe uma essência interior que é posta a descoberto por meio dos atos. Ao contrário, são esses atos corporais, estéticos e linguísticos, que fazem o gênero (2006, p. 25-26).

Assim, as transexuais enquadram-se na teoria queer, sobre identidade de gênero, sendo consideradas um terceiro gênero, por exemplo, pois não se enquadram como homem ou mulher. Elas nascem com um determinado sexo imposto no nascimento e não se identificam com ele, tampouco com seu corpo, então passam a se comportarem e a se declararem do sexo oposto.

A referida teoria queer se trata de uma política de resistência para unificar os anseios de gays, lésbicas, travestis, transexuais, bissexuais, os quais são estigmatizados. Se baseia em

\footnotetext{
${ }^{6}$ Lésbica se trata do sexo feminino que possui atração sexual pelo mesmo sexo, sendo os gays de igual forma, contudo, são do sexo masculino e atraem-se pelo idêntico sexo, ambos homossexuais. As travestis são pessoas que se vestem de feminino e querem ser tratadas como tal, sem possuírem horror ao seu corpo de nascimento, já as drag são artistas transformistas que se vestem do gênero diferente do seu, mas não homossexuais (JESUS, 2012).
} 
discursos que questionam as normas hegemônicas de gênero binário, subvertendo sobre tais padrões, encabeçada por Judith Butler e discorrida por diversos outros autores.

Além do mais, não podem ser consideradas como homossexuais, visto que estes se restringem "ao âmbito das relações afetivas e sexuais, ou seja, o indivíduo apenas elege uma pessoa com uma constituição genital semelhante a sua como objeto erótico, não apresentando repúdio pelo seu próprio corpo, nem a pretensão de transformá-lo" (SOUZA, p. 30).

Não podem ser confundidas também com as travestis, pois apesar de ambas se vestirem como mulheres e manterem relações sexuais com homens, as travestis não abominam seu corpo, ao contrário, elas tem orgulho do seu órgão genital e não cogitam mudança, apenas por determinado lapso de tempo preferem ser outra pessoa (SOUZA, 2012).

Para Marinho: "São pessoas em que o sexo biológico não se compatibiliza com o sexo psíquico, fazendo com que busquem constantemente a adequação do seu corpo à mente, na maioria das vezes estas pessoas desejam e buscam realizar a cirurgia de redesignação de sexo por possuírem ojeriza ao seu órgão sexual” (2016, p. 262).

Com isso, as transexuais se distinguem dos gays, lésbicas e travestis e as mesmas não apresentam nenhuma patologia biológica, mas possuem convicção de que não pertencem ao corpo o qual nasceram, sendo que algumas optam por passarem por cirurgia para aderirem ao sexo ao qual almejam, para encontrarem um sentido de identidade (BENTO, 2006).

No contexto social, as transexuais são excluídas de forma extrema, sem acesso a direitos civis básicos, como o reconhecimento de sua identidade de gênero. Sofrem violências físicas, psicológicas e simbólicas constantemente, devido ao discurso do ódio contra elas, denominado de "transfobia". Sofrem preconceitos pelos meios de comunicação também, especialmente nas redes sociais (JESUS, 2012).

$\mathrm{Na}$ família, muitas vezes não possuem o apoio familiar e sofrem discriminação e violência dentro da própria casa. Assim também na escola. Na vida adulta, passam por diversas situações discriminatórias, especialmente quanto ao uso do banheiro, à ridicularização pelo nome social e no próprio setor de saúde quando pretendem realizar a cirurgia de mudança de sexo (BENTO, 2008).

Por fim, as transexuais ultrapassam o conceito binário de gênero masculino/feminino, possuem sua própria identidade e pertencem ao sexo oposto do designado em seu nascimento, alguns realizam a cirurgia de redesignação de sexo e outras não; contudo, a realização da intervenção cirúrgica não é necessária para considerar-se como transexual. 
Feitos esses aportes, agora adentrar-se-á no tema do trabalho como um meio de inclusão socioeconômica, haja vista a vulnerabilidade e marginalização das transexuais na sociedade.

\subsection{Inclusão socioecônomica das transexuais pelo mercado de trabalho}

O Brasil, após o advento da Constituição Federal de 1988, instituiu e definiu vários aspectos na esfera de assistência social. Iniciou assim a criação de políticas públicas, também definidas como obrigações positivas, criando, por exemplo, o Programa Bolsa Família (COUTINHO, 2013, p. 109-110).

A propósito, Rawls aborda a temática das políticas públicas (2000), tratando acerca das parcelas distributivas, requerendo atenção do Estado para garantir direitos, sendo que todos são sujeitos de direitos e deveres e como tal devem ser tratados. Do ponto de vista jurídico, existe um "mínimo social"7 . Trata-se de algo intrinsecamente ligado à realização dos direitos fundamentais, que representam a concretização do princípio da dignidade da pessoa humana.

Nesse contexto, as pessoas transexuais sofrem diversas discriminações, sejam pela sociedade, família, amigos e no próprio mercado de trabalho. Por se considerarem e pertencerem ao sexo oposto do designado em seu nascimento e não aceitarem conviver com seu corpo, optam por aderirem ao outro sexo.

As transexuais vivem marginalizadas, pois:

(...) o corpo é um texto socialmente construído, um arquivo vivo na história do processo de (re)produção sexual. Neste processo, certos códigos naturalizam-se, outros, são ofuscados e/ou sistematicamente eliminados, postos às margens do humanamente aceitável, como acontece com as pessoas transexuais (BENTO, 2008, p. 30).

Para Longaray e Ribeiro:

As transexuais e as travestis são alvos dessa investigação por serem entendidas como corpos abjetos, sendo, para muitos/as, consideradas aberrações, pois desafiam a heteronormatividade, ou seja, são produzidos fora da inteligibilidade social, incoerentemente em relação às normas hegemônicas. Provocam, muitas vezes, repulsa na sociedade $(2016$, p. 763$)$.

\footnotetext{
${ }^{7}$ Para o autor o governo deve assegurar um mínimo social, seja por salário-família e subvenções especiais em casos de doença e desemprego, seja mais sistematicamente por meio de dispositivos tais como um suplemento gradual de renda.
} 
Elas sofrem preconceitos por não se adequarem ao padrão comportamental e de gênero que a sociedade impõe. Segundo Ferraz: "Essas pessoas descumprem os códigos sociais ao expressarem um gênero sexual que não corresponde ao que seria "próprio" do seu sexo biológico [...]" (2013, p. 219).

Pois bem, o trabalho é um meio de inclusão socioeconômica, tanto para o cidadão possuir renda para seu próprio sustento como para estar inserido na sociedade por meio do labor, para satisfação pessoal e profissional. Segundo Cecato (2011), o trabalho representa um bem-estar econômico, que além da satisfação serve como um instrumento de inserção social.

O labor também concretiza a dignidade do ser humano, direito este consagrado no artigo $6^{\circ}$ da Constituição Federal brasileira ${ }^{8}$. Fonseca assevera que se trata: "de um direito vinculado à vida, pois sem trabalho as pessoas não tem como proporcionar uma vida digna para si e para sua família” (2014, p. 99).

De acordo com Delgado:

O trabalho, em especial o regulado (o emprego, em suma), por ser assecuratório de certo patamar de garantias do ser humano, constitui-se no mais importante veículo de afirmação socioeconômica da grande maioria dos indivíduos componentes da sociedade capitalista, sendo desse modo, um dos mais relevantes (senão o maior deles) instrumentos de afirmação da democracia na visão social (2008, p. 21).

Devido ao preconceito contra as transexuais, as mesmas possuem dificuldades imensas de ingressarem no mercado de trabalho formal. Os motivos são por não se enquadrarem ao modelo de pessoa imposto pela sociedade, por vestirem-se em conformidade com o sexo oposto ao seu e por possuírem um nome social ${ }^{9}$ distinto do registro civil.

Ainda, a expulsão de casa, a falta de apoio familiar, a evasão escolar, devido ao preconceito e assédio que essas pessoas sofrem, atrelado à falta de políticas públicas e iniciativa do Estado e das instituições de ensino, também são fatores que contribuem para as dificuldades de inserção no mercado de trabalho formal (SOUZA, 2012).

Assim, elas ficam invisíveis para o Estado e a sociedade, à margem, socorrendo-se muitas vezes a trabalhos informais, como por exemplo, a prostituição, a qual se torna uma fonte de renda para sua subsistência.

\footnotetext{
${ }^{8}$ Art. $6^{\circ}$ São direitos sociais a educação, a saúde, a alimentação, o trabalho, a moradia, o transporte, o lazer, a segurança, a previdência social, a proteção à maternidade e à infância, a assistência aos desamparados, na forma desta Constituição.

9 Nome social é o autodesignado pela transexual a fim de ser reconhecida socialmente, nome, este, adotado diferente do que consta no registro civil, o qual será escolhido pelo gênero que ela se identificará, vestindo-se e comportando-se desta maneira.
} 
As transexuais sofrem com a dificuldade de serem empregadas, mesmo que tenham qualificação, e na maioria dos casos são excluídas das escolas, repudiadas no mercado de trabalho formal e forçadas a viveram à margem da sociedade, geralmente como prostitutas (BENTO, 2008).

Ainda, criou-se vários estereótipos para as transexuais, como, por exemplo, ser uma pessoa vadia, desbocada, sexualmente ativa e extravagante. Devido à competitividade mercantil e também a esta falácia, o mercado de trabalho atua no sentido de excluir e discriminar as transexuais, tanto no momento do processo de seleção ao ingresso no trabalho quanto sua manutenção no emprego (SILVA, 2015).

É necessário uma atuação do Estado e de instituições para criação de políticas públicas de inclusão das transexuais no mercado de trabalho formal.

Para Prado e Dangelo (2017, p. 74-75), incluir a pessoa transexual no mercado de trabalho é dar efetividade aos direitos fundamentais, nomeadamente à dignidade da pessoa humana e à isonomia, bem como ao princípio da Proteção previsto no Direito do Trabalho.

Nesse viés, conceitua-se o princípio da proteção segundo Delgado: [...] este princípio que o Direito do Trabalho estrutura em seu interior, com suas regras, institutos, princípios e presunções próprias, uma teia de proteção à parte hipossuficiente na relação empregatícia - o obreiro - , visando retificar (ou atenuar), no plano jurídico, o desequilíbrio inerente ao plano fático do contrato de trabalho (2008, p. 213).

A Constituição Federal brasileira preza por uma sociedade justa e solidária. Assim, é necessária a criação de ações afirmativas, também denominadas como discriminação positiva, a fim de igualar os direitos das pessoas que estão, materialmente, em posição desigual (GOLDSCHMIDT, 2008).

Há muito a ser caminhado para alcançar a igualdade material para tratamento em diversas áreas para as transexuais, especialmente no campo do Direito do Trabalho. Assim (SILVA, 2015), é necessário desenvolver políticas públicas que favoreçam o acesso e permanência no mercado de trabalho, que evitem discriminações, assédios, promovam promoção de cargos, enfim, que visem diminuir a discriminação contra as pessoas transexuais.

Com isso, é necessário que o Estado implemente políticas públicas que afirmem a dignidade das pessoas transexuais, criando postos de trabalho para este grupo, medidas para ingresso e manutenção no mercado formal de trabalho. A título de exemplo, criar cotas mínimas para ingresso no mercado formal de trabalho, à semelhança do que ocorre para os 
(as) trabalhadores (as) deficientes, conforme artigo 93 da Lei 8.213/91 ${ }^{10}$. Talvez esta não seja a solução para o problema de forma permanente, apenas temporário para tentar inserir as pessoas transexuais no mercado formal de trabalho, uma medida impositiva para as empresas que não possuem consciência acerca de identidade de gênero.

A educação seria o meio mais eficaz para a inclusão deste grupo, criando políticas públicas que promovam educação de gênero, para conscientização da sociedade acerca de vários mitos, objetivando a inclusão das pessoas transexuais em várias esferas da sociedade, especialmente no âmbito do mercado formal de trabalho.

Neste viés, há o projeto de Lei n. 5002/2013 tramitando no Congresso Nacional Brasileiro sobre identidade de gênero e alteração do prenome para incluir o nome social das transexuais também como hipótese de mudança no registro civil, além daquele previsto apenas como apelidos públicos notórios.

Ademais, no âmbito internacional é mister trazer à tona a Convenção Americana de Direitos Humanos formulada no ano de 1969, também conhecida como Pacto de San José da Costa Rica, ratificada pelo Brasil em 25 de setembro de 1992, que prevê deveres para os Estados participantes, especialmente acerca do cerne do artigo, sobre o princípio de não discriminar as pessoas por motivo de sexo, conforme assevera o artigo $1^{{ }^{11}}$.

Por fim, a inclusão da transexual no mercado de trabalho proporciona inclusão econômica, visto que lhe trará rendimentos pelo labor prestado e, inclusão social, haja vista que estará inserida na sociedade, prestando seus serviços de forma digna em igualdade de condições com os demais trabalhadores, sem discriminação.

\footnotetext{
${ }^{10}$ Art. 93. A empresa com 100 (cem) ou mais empregados está obrigada a preencher de $2 \%$ (dois por cento) a $5 \%$ (cinco por cento) dos seus cargos com beneficiários reabilitados ou pessoas portadoras de deficiência, habilitadas, na seguinte proporção: I - até 200 empregados......2\%; II - de 201 a $500 \ldots . . . .3 \%$; III - de 501 a $1.000 \ldots . . . . . .4 \%$; IV - de 1.001 em diante.........5\%.

${ }^{11}$ Artigo $1^{\circ}$ - Obrigação de respeitar os direitos. 1. Os Estados-partes nesta Convenção comprometem-se a respeitar os direitos e liberdades nela reconhecidos e a garantir seu livre e pleno exercício a toda pessoa que esteja sujeita à sua jurisdição, sem discriminação alguma, por motivo de raça, cor, sexo, idioma, religião, opiniões políticas ou de qualquer outra natureza, origem nacional ou social, posição econômica, nascimento ou qualquer outra condição social. 2. Para efeitos desta Convenção, pessoa é todo ser humano.
} 


\section{Conclusão}

Conforme o exposto, as transexuais sofrem discriminação, apesar de existirem direitos positivados na Constituição Federal brasileira e até em tratados e convenções internacionais sobre o direito da antidiscriminação, no sentido de que todas as pessoas merecem igualdade de tratamento, independentemente do sexo e identidade de gênero.

As transexuais sofrem discriminações das mais diversas formas, e vivem à margem da sociedade, pois possuem sérias dificuldades de ingressarem no mercado de trabalho formal ou lá permanecerem, devido à discriminação existente contra elas, pois são consideradas aberrações segundo o padrão cultural imposto.

O trabalho formal se apresenta como um meio de inclusão socioeconômica que traz dignidade para as pessoas transexuais, pois o labor traz renda fixa e insere os(as) trabalhadores(as) na sociedade, de forma a proporcionar uma qualidade de vida para si e sua família.

Ocorre que o acesso ao trabalho formal às pessoas transexuais é precário, sendo necessário uma intervenção positiva do Estado, a quem compete implementar políticas públicas para efetivar o direito das transexuais ingressar e permanecer no mercado formal de trabalho, proporcionando dignidade e igualdade material para esse grupo pela inclusão socioeconômica.

Por fim, as desigualdades são gritantes no Brasil e no mundo e, se já existe discriminação no mercado de trabalho entre homens e mulheres, este dado é ainda pior quando ele se refere às transexuais, as quais são excluídas da sociedade por não pertencerem ao binarismo imposto culturalmente, havendo, assim, necessidade de ações afirmativas pautadas no princípio da antidiscriminação para dar efetividade aos direitos das pessoas transexuais.

\section{Referências}

BADINTER, E. XY: sobre a identidade masculina. Rio de Janeiro: Nova Fronteira, 1993.

BEAUVOIR, Simone de. O segundo sexo: a experiência vivida. 3. ed. Rio de Janeiro: Nova Fronteira, 2016.

BENTO, Berenice. A reinvenção do Corpo: sexualidade e gênero na experiência transexual. Rio de Janeiro: Garamond, 2006.

BRASIL. Constituição da República Federativa do Brasil. de 05 de outubro de 1988. Disponível 
$<$ http://www.planalto.gov.br/ccivil_03/constituicao/constituicaocompilado.htm $>$ Acesso em: $10 / 10 / 2018$.

Decreto no 62.150, de 19 de janeiro de 1968. Promulga a Convenção $n^{0} 111$ da OIT sobre discriminação em matéria de emprego e profissão. Planalto. Brasília, DF, Disponível em: <http://www.planalto.gov.br/ccivil_03/decreto/1950-1969/d62150.htm>. Acesso em: 09 out. 2017.

Lei 8.213/91, de 24 de julho de 1991. Planalto. Brasília, DF, Disponível em: $<$ http://www.planalto.gov.br/Ccivil_03/leis/L8213cons.htm>. Acesso em: 08 de fev. 2018.

BUTLER, Judith. Problemas de gênero: feminismo e subversão da identidade. 10 ed. Rio de Janeiro: Civilização Brasileira, 2016.

CECATO, Maria Aurea Baroni. Interfaces do Trabalho com o Desenvolvimento: Inclusão do Trabalhador Segundo os Preceitos da Declaração de 1986 da Onu Prima Facie, João pessoa, V. 11, N. 20, ANO 2011, Jan/jun, 2012, p. 23-42.

COSTA RICA. Convenção Americana Sobre Direitos Humanos. San José, Disponível em: $<$ https://www.cidh.oas.org/basicos/portugues/c.convencao_americana.htm>. Acesso em: 12 fev. 2018.

COUTINHO, Diogo R.. Direito, Desigualdade e Desenvolvimento. São Paulo: Saraiva, 2013.

DELGADO, Maurício Godinho. Curso de direito do trabalho. 7. ed. São Paulo: LTr, 2008.

FERRAZ, Carolina Valença, LEITE, George Salomão, LEITE, Glauber Salomão. Manual dos direitos da mulher. Rio de Janeiro: Saraiva, 2013.

FONSECA, Maria Hemília. Direito ao trabalho: um direito fundamental. São Paulo, LTr, 2014.

GOLDSCHMIDT, Rodrigo; RENCK, Maria Helena Pinheiro. Discriminação contra as mulheres no trabalho e ações afirmativas. 22. ed. Curitiba: Multideia, 2016.

JESUS, Jaqueline Gomes de. Orientações sobre identidade de gênero: conceitos e termos. 2. ed. Brasília: EDA/FBN, 2012. Disponível em: $<$ http://www.diversidadesexual.com.br/wp-content/uploads/2013/04/GÊNERO-

CONCEITOS-E-TERMOS.pdf >. Acesso em: 08 fev. 2018.

LONGARAY, Deise Azevedo; RIBEIRO, Paula Regina Costa. Travestis e transexuais: corpos (trans)formados e produção da feminilidade. Revista Estudos Feministas, [s.1.], v. 24, n. 3, p.761-784, dez. 2016. FapUNIFESP (SciELO). http://dx.doi.org/10.1590/1806-95842016v24n3p761.

MARINHO, Neumalyna Lacerda Alves Dantas. A EXCLUSÃO DAS PESSOAS TRANS DO MERCADO DE TRABALHO E A NÃO EFETIVIDADE DO DIREITO FUNDAMENTAL AO TRABALHO. Revista de Gênero, Sexualidade e Direito, v.2, n. 1, p. 261-277, jan/jun. 2016.

MOREIRA, Adilson José. O que é discriminação? Belo Horizonte: Letramento, 2017. 
PRADO, Anna Priscylla Lima; DANGELO, Isabele Bandeira de Moraes. A INCLUSÃO NO MERCADO DE TRABALHO DA PESSOA TRANSGÊNERO E A "DOLOROSA" ARTE DE SER NORMAL. Revista de Gênero, Sexualidade e Direito, Brasília, v. 3, n. 1, p.58-78, jun. 2017.

RAWLS. John. Uma Teoria da Justiça. Martin Fontes: São Paulo, 2000.

RIOS, Roger Raupp. Direito da antidiscriminação: discriminação direta, indireta e ações afirmativas. Porto Alegre: Livraria do Advogado Editora, 2008.

SILVA, Sofia Vilela de Moraes. Discriminação por identidade de gênero no direito do trabalho : a desconstrução do dispositivo binário centrado na polaridade homem/mulher para ampliar os cânones da proteção. 2015. 196 f. Tese (Doutorado) - Curso de Direito, UFPE, Recife, 2015. Disponível em: https://repositorio.ufpe.br/handle/123456789/18312

SOUZA, Heloisa Aparecida de. Os desafios do trabalho na vida cotidiana de mulheres transexuais. 2012. 128 f. Dissertação (Mestrado) - Curso de Psicologia, Centro de Ciências da Vida, Puc, Campinas, 2012. Disponível em: <http://www.bibliotecadigital.puccampinas.edu.br/tde_arquivos/6/TDE-2013-02-05T062126Z-1768/Publico/Heloisa Aparecida de Souza.pdf $>$. Acesso em: 10 set. 2017.

UNITED NATIONS. International Covenant on Economic, Social and Cultural Rights. United Nations - Human Rights - Office of the High Commissioner for Human Rights, 3 de Janeiro de 1976.10 Disponível em: $<$ http://www.ohchr.org/EN/ProfessionalInterest/Pages/CESCR. aspx $>$. Acesso em: 15 jan. 2018.

WITTIG, Monique. EI pensamiento heterosexual y otros ensayos. Madrid: Egales, 2006. 